\title{
Pre-Service Biology Teachers' Attitudes Towards Math: Using the Covid-19 Case in Calculus Course
}

\author{
Kimura Patar Tamba ${ }^{1, *}$ \\ ${ }^{1}$ Department of Mathematics Education, Universitas Pelita Harapan \\ *Corresponding author. Email: kimura.tamba@uph.edu
}

\begin{abstract}
Mathematics, especially calculus, cannot be separated in the field of biology. Mathematical abilities are essential in understanding biological phenomena. However, pre-service biology teachers' attitudes toward math tend to be negative. For this reason, an interdisciplinary approach is needed so that that pre-service biology teachers can see the relationship between biology and mathematics. An interdisciplinary approach can be in the form of case studies. This study explores the pre-service biology teachers' attitudes toward math(calculus), which is taught using the Covid-19 case study. Data were collected using a reflection sheet and a questionnaire. On the reflection sheet, pre-service biology teachers are asked to write down their reflections on mathematics in biology after attending a lecture session. The questionnaire uses a Likert scale to see their attitude toward math before and after completing the course session. The data from the reflection sheet were analyzed qualitatively descriptively by using coding. Meanwhile, the data from the questionnaire were analyzed using descriptive statistics. The results showed pre-service biology teachers' attitudes toward math (calculus) tend positive in two aspects. Pre-service biology teachers can see a connection and the importance of calculus in biology and interest in calculus. But, pre-service biology teachers have negative attitudes in aspect Perceived cost.
\end{abstract}

Keywords: Interdisciplinary approach, Calculus, Covid-19, Attitudes towards math.

\section{INTRODUCTION}

Various studies and recommendations suggest that undergraduate biology students should develop quantitative skills and apply them to biological contexts [1], [2], [3], [4]. Therefore, various research or biology communities have called for reforms in biology education to encourage more interdisciplinary and strengthening quantitative skills [1], [2], [3], [4]. Calculus is a significant component in developing undergraduate biology students' quantitative skills because almost all biological domains require calculus [5], [6], [7], [8].

However, negative student attitudes toward math are challenging for developing quantitative skills in biology education [9], [10], [11]. Various studies reveal and confirm the existence of negative student attitudes toward math [12], [13], [14], [15]. Negative student attitudes toward math imply a low desire to engage in learning activities, develop quantitative abilities, and a desire to continue working in biology [12], [14], [15]. Conversely, positive student attitudes toward math are essential for developing biology majors' quantitative skills because they affect motivation. Students' performance quantitative skills depend on motivation influenced by their attitudes toward math [9], [10].

To reduce and avoid negative attitudes and promote positive attitudes toward math, various research and biology education communities are proposing interdisciplinary mathematics and biology, thereby increasing the integration of the two [1], [2], [11], [12], [14], [15], [16], [17], [18]. One form of interdisciplinary implementation between mathematics and biology is the use of real-world problems or the use of a case study in calculus courses [12], [16], [19]. The use of real-world problems is an authentic interdisciplinary nature of modern biology [12]. Previous research has shown this strategy can change perceptions and attitudes [16], [20]. Also, a previous study suggested that using genuine real-world context problems could encourage appreciation of mathematics.

Genuine real-world context problems will enable students to see the interdisciplinary between mathematics and biology more clearly when dealing with their life problems. From the end of 2019 until 
now, everyone has faced cases of the Covid-19 pandemic. Not only information but this case also directly affects the life of pre-service biology teachers (education, social, etc.). Meanwhile, the case of the Covid-19 pandemic is a case that is closely related to biology and mathematics. Thus, it can be said that the Covid-19 pandemic is a genuine real-world context problem for the current pre-service biology teachers. Various previous studies have not used genuine realworld context problems [16], [20]. The use of the Covid-19 pandemic as a genuine real-world context problem is essential because pre-service biology teachers will teach biology to students. This approach means that when they have a learning experience using genuine real-world context problems, they will easily implement the same strategy in the class they will teach.

This study explores pre-service biology teachers' attitudes toward math, which are taught using covid-19 real-world problems. In detail, this study will describe the pre-service biology teachers' attitudes toward math after they get a calculus course taught using the pandemic covid-19 as a genuine real-world context problem. Therefore, the question that guides this research is how the pre-service biology teachers' attitudes toward math after being taught using the pandemic covid-19 case in calculus course approach?

\section{METHOD}

This research uses a descriptive method. The descriptive method was chosen because it describes the pre-service biology teachers' attitudes toward math after being taught using the pandemic covid-19 case in the calculus course approach.

\subsection{Course Description}

Calculus for biology is a course aimed directly at encouraging the quantitative skills of pre-service biology teachers. The courses in previous years were still demonstrating the mathematical foundations that underpin a range of science disciplines. Currently (in this study), a different approach is being used by strengthening the interdisciplinary nature of this course by enhancing the relationship between calculus and the biology context. One of them is by using the Covid-19 pandemic as a genuine real-world context problem. The course (specifically for this research) runs for three teaching weeks, with 3 hours of lecture and 2 hours of tutorial per week. Table 1 describes in detail the lecture descriptions. The course uses desmos tools to construct the activities by researchers (viewed by searching for activity on the web desmos with the keyword "Kalkulus untuk Biologi").

\subsection{Participants, Instrument, and Data Analysis}

Participants in this study were 23 pre-service biology teachers in 2019 (5 men, 18 women). All participants have enrolled in the calculus for a biology course. Data for pre-service biology teachers' attitudes toward math were collected using a reflection sheet and a questionnaire. The reflection sheet contains views of pre-service biology teachers about lectures. The guiding question in this reflection sheet's preparation is, how do you think about this lecture? How did you feel during the course? What do you think about math after the course?

The questionnaire used in this study was The Math Biology Values Instrument (MBVI) developed by [9]. This questionnaire contains 11 items, which are grouped into three aspects, namely Interest (4 items), Utility value (4 items), and Perceived cost (3 items). MBVI uses a Likert scale with a 5-point scale, from 1 (strongly disagree) to 5 (strongly agree). The original questionnaire (can be found at [9]) translated into Bahasa.

Before use, the validity and reliability of the MBVI questionnaire were tested. The test shows the Pearson correlation value for items $1-10$ is in the range of 0.243 to 0.805 and is significant for $\alpha=0.05$. This value indicates that the validity of the instrument is acceptable. While item no 11 has a Pearson correlation value of 0.085 , it is not significant at $\alpha=0.05$.

Table 1. Course description

\begin{tabular}{|c|c|c|c|c|}
\hline Week & Real-World Context & Mathematical concepts & Biological concepts & Approach \\
\hline I & $\begin{array}{l}\text { Trends in the Covid-19 } \\
\text { Case Rate in Indonesia }\end{array}$ & \begin{tabular}{|l} 
Function, $\quad$ Graph, \\
Modelling
\end{tabular} & & $\begin{array}{l}\text { Analyze, interprets, and } \\
\text { represent mathematical } \\
\text { modeling in the graph using } \\
\text { desmos }\end{array}$ \\
\hline II & $\begin{array}{l}\text { Trends in the Covid-19 } \\
\text { Case Rate in Indonesia, } \\
\text { Covid-19 spread }\end{array}$ & Function and Graph & Epidemiology & $\begin{array}{l}\text { Analyze function, graph } \\
\text { function using desmos }\end{array}$ \\
\hline III & $\begin{array}{l}\text { Trends in the Covid-19 } \\
\text { Case Rate in Indonesia }\end{array}$ & Kind of Function & & $\begin{array}{l}\text { Analyze graph of covid-19 } \\
\text { case rate using desmos }\end{array}$ \\
\hline
\end{tabular}


Therefore item no 11 (perceived cost) was removed (not used). Thus MBVI has ten items. Cronbach's Alpha value of 0.872 (greater than 0.5 ) indicates that the questionnaire has a high internal consistency level (reliability). The pretest and posttest data were collected using Microsoft form

Data were analyzed qualitatively descriptive. Data from the reflection sheet were analyzed using deductive coding [22]. The coding used follows three aspects of MBVI, namely interest, utility value, and perceived cost. Reflections will be categorized into "positive" and "negative" attitudes for each aspect. The questionnaire's data were analyzed using simple descriptive statistics, including mean, max-min, and std. deviation. The analysis was performed using SPSS 20.0.

\section{RESULTS AND DISCUSSION}

The study results are presented in three sections based on the attitudes toward math aspects of the MBVI. The first part describes the aspects of interest. The second part reveals aspects of utility value, and the third part concerns perceived costs. Each part of the teachers' attitudes toward math was described based on the data analysis questionnaire and reflection sheet results. Table 2 is the results of the descriptive analysis of the data from the questionnaire.

Table 2. Description of pre-service biology teachers' attitudes toward math based on questionnaire

\begin{tabular}{|l|l|l|l|l|}
\hline Attitude & Min & Max & Mean & Std.Dev \\
\hline Interest & 3.25 & 5.00 & 4.17 & 0.452 \\
\hline Utility value & 3.75 & 5.00 & 4.30 & 0.44 \\
\hline Perceived cost & 2.00 & 5.00 & 3.92 & 0.79 \\
\hline
\end{tabular}

Table 3 shows the coding results of the reflection sheet data based on the MBVI aspect. The coding results showed that even though questions guided them, not all pre-service biology teachers expressed their interest in the course because of the COVID-19 pandemic context. The pre-service does write down their interest in the course, but it is related to tools, learning approaches, and classroom management. The theme of this reflection is not categorized as the aspect of interest in MBVI. The same way is done in the other two aspects.

\subsection{Interest}

Attitudes toward math based on the aspect of interest means the enjoyment a student experiences from engaging in a task [9], [23]. Descriptive analysis of the aspects of interest is shown in Table 1. The mean of interest is 4.17, which means that the pre-service biology teachers have a high level of interest in mathematics. The high interest in mathematics shows a positive attitude towards mathematics [9]. Thus, this study's results indicate that the pre-service biology teacher has a positive attitude towards mathematics after attending the course. A positive attitude based on the interest aspect means that the pre-service biology teachers feel curious, interested, amazing, and enjoy using mathematics to understand biology. These results show that pre-service biology teachers have a positive attitude toward math after attending the course using the pandemic covid-19 case in the calculus course approach.

This result is following the reflection sheet results written by pre-service biology teachers after attending the lecture. All pre-service biology teachers noted that they were interested and challenged because they used mathematics to understand the biology case (see table 2). Pre-service biology teachers are interested in calculus because they can understand biological cases and relate to everyday life (genuine real-world context problems).

Thus, this study's finding is that pre-service biology teachers have positive attitudes toward math in the interest aspect after attending lectures using the pandemic covid-19 approach as a genuine real-world context problem. This means that the pandemic covid19 approach as a genuine real-world context problem impacts the emergence of positive attitudes in terms of 
Table 3. Coding reflection sheet data

\begin{tabular}{|c|c|c|c|}
\hline \multicolumn{2}{|c|}{ Attitude } & Examples of statements & Freq \\
\hline \multirow[t]{2}{*}{ Interest } & Positive & $\begin{array}{l}\text { In my opinion, most of what was learned were new, which } \\
\text { made me increasingly challenged to study calculus more and } \\
\text { more actively. }\end{array}$ & 12 \\
\hline & Negative & - & 0 \\
\hline \multirow[t]{2}{*}{ Utility value } & Positive & $\begin{array}{l}\text { I used to think that calculus was difficult and would not be } \\
\text { discussed much in biology. It turns out that calculus is very } \\
\text { close to biology, especially in predicting data, and calculus is } \\
\text { very much needed. }\end{array}$ & 19 \\
\hline & Negative & - & 0 \\
\hline \multirow[t]{2}{*}{ Perceived cost } & Positive & $\begin{array}{l}\text { From each task given, I feel empowered to understand the } \\
\text { concept better and find solutions to solve it shortly, for } \\
\text { example, in viewing journal biology. }\end{array}$ & 4 \\
\hline & Negative & $\begin{array}{l}\text { The thing that has become difficult for me is understanding } \\
\text { mathematical concepts and then connecting them with biology. }\end{array}$ & 11 \\
\hline
\end{tabular}

This finding is supported by the analysis of the reflection sheet data. Table 2 shows the themes that appear on the reflection sheet relating to utility value, namely the use of calculus in everyday life, specifically in understanding and dealing with the Covid-19 pandemic. The pre-service biology teachers' reflection results on the course also show that the use of genuine real-world context problems helps them have positive utility values for calculus (mathematics).

\subsection{Perceived Cost}

Attitudes toward math based on perceived cost means that perceived cost involves the negative aspects of engaging in a task. Cost includes 1) extra effort required for a task, 2) the loss of opportunities that result from engaging in a task, and 3) the emotional toll of a task [9], [23]. Descriptive analysis in table 1 shows the mean of this aspect of 3.92. The mean value greater than 3 indicates that the pre-service biology teachers have negative attitudes to mathematics regarding the perceived cost. This means that the pre-service biology teachers see that it takes more effort in understanding calculus when it is taught with a genuine real-world context problem approach.

Analysis of the reflection sheet also shows the same thing. Most of them have negative attitudes in terms of the perceived cost. According to the pre-service biology teachers, integrating biology and mathematics using the pandemic covid-19 as a genuine real-world context problem is more difficult than those without.

The three findings above are consistent with previous research [9], [11], [15], [16], [19], [24]. Previous research has also revealed that the use of realworld context problems encourages positive attitudes in terms of interest in math. Also, the finding that the preservice biology teachers' attitudes toward math in terms of perceived cost tends to be negative is consistent with previous studies [9], [16], [24], [25]. Attitudes toward math that tend to be negative in terms of perceived cost can be caused by feelings of frustration and being overwhelmed by the course's workload and fast pace [16]. Based on the reflection results, these negative attitudes can happen because the pre-service biology teachers are not familiar with the approach, integrating biology and mathematics using the pandemic covid-19 as a genuine real-world context problem.

This research contributes to the body of knowledge and research of undergraduate biology attitudes toward math in the context of pre-service biology teachers. The research also contributes because it uses a genuine realworld context problem approach, wherein previous studies were only limited to real-world context problems. The use of the Covid-19 pandemic as a genuine real-world context problem allows pre-service biology teachers to experience integrating mathematics into biology first-hand.

\section{CONCLUSION}

This study concludes that the pre-service biology teachers' attitudes toward math (calculus) tend to be positive in two aspects. The two aspects are interest and utility value. This means that the pre-service biology teacher is interested in using and integrating mathematics (in this case, calculus) on the topic of biology. The utility value aspect means that pre-service biology teachers can see a connection and the importance of calculus in biology. Meanwhile, the perceived cost aspect, pre-service biology teachers have negative attitudes toward math. This means that using 
the Covid-19 pandemic as a genuine real-world context problem on the course is still difficult and requires extra effort for the pre-service biology teachers. These findings provide practical implications in the process of studying calculus for biology. The use of a genuine realworld context problem is very important to consider in compiling didactic designs on calculus for biology courses.

\section{REFERENCES}

[1] S. Hester, S. Buxner, L. Elfring, And L. Nagy, Integrating Quantitative Thinking Into An Introductory Biology Course Improves Students' Mathematical Reasoning In Biological Contexts, CBE Life Sciences Education 13(1) (2014) 54-64. Doi: 10.1187/Cbe.13-07-0129

[2] T. Woodin, V. Celeste Carter, And L. Fletcher, Vision And Change In Biology Undergraduate Education, A Call For Action-Initial Responses, CBE Life Sciences Education 9(2) (2010) 7173. Doi: 10.1187/Cbe.10-03-0044.

[3] Nrc, A New Biology For The 21 St Century National Academies Press, Washington, 2009.

[4] Nrc, Bio2010: Transforming Undergraduate Education For Future Research Biologists. National Academies Press, Washington, 2003.

[5] J. E. Cohen, Mathematics Is Biology's Next Microscope, Only Better; Biology Is Mathematics' Next Physics, Only Better," Plos Biol. 2(12) (2004). DOI: 10.1371/Journal.Pbio.0020439.

[6] D. M. Bressoud, Insights From The MAA National Study Of College Calculus, The Mathematics Teacher109(3) (2015) 178-185.

[7] D. M. Bressoud, M. P. Carlson, V. Mesa, And C. Rasmussen, The Calculus Student: Insights From The Mathematical Association Of America National Study, International Journal of Mathematical Education in Science and Technology 44(5) (2013) 685-698. DOI: 10.1080/0020739x.2013.798874.

[8] R. T. Taylor, P. R. Bishop, S. Lenhart, L. J. Gross, And K. Sturner, Development Of The Biocalculus Assessment (BCA), CBE Life Sciences Education 19(1) (2020) 1-12. DOI: 10.1187/Cbe.18-10-0216.

[9] S. E. Andrews, C. Runyon, And M. L. Aikens, The Math-Biology Values Instrument: Development Of A Tool To Measure Life Science Majors' Task Values Of Using Math In The Context Of Biology, CBE Life Sciences Education 16(3) (2017) 1-12. DOI: 10.1187/Cbe.17-03-0043.

[10] M. Colon-Berlingeri And P. A. Burrowes,
Teaching Biology Through Statistics: Application Of Statistical Methods In Genetics And Zoology Courses, CBE Life Sciences Education 10(3) (2011) 259-267. Doi: 10.1187/Cbe.10-11-0137.

[11] K. V. Thompson Et Al., Infusing Quantitative Approaches Throughout The Biological Sciences Curriculum, International Journal of Mathematical Education in Science and Technology 44(6) (2013) 817-833. DOI: 10.1080/0020739x.2013.812754.

[12] K. E. Matthews, P. Adams, And M. Goos, Using The Principles of Bio2010 To Develop An Introductory, Interdisciplinary Course For Biology Students, CBE Life Sciences Education 9(3) (2010) 290-297. DOI: 10.1187/Cbe.10-030034.

[13] J. R. Mcginnis, S. Kramer, G. Shama, A. O. Graeber, C. A. Parker, And T. Watanabe, Undergraduates' Attitudes And Beliefs About Subject Matter And Pedagogy Measured Periodically In A Reform-Based Mathematics And Science Teacher Preparation Program, Journal of Research in Science Teaching 39(8) (2002) 713-737. Doi: 10.1002/Tea.10042.

[14] L. Poladian, Engaging Life-Sciences Students With Mathematical Models: Does Authenticity Help? International Journal of Mathematical Education in Science and Technology 44(6) (2013) 865-876. DOI: 10.1080/0020739x.2013.811301.

[15] L. P. Wachsmuth, C. R. Runyon, J. M. Drake, And E. L. Dolan, Do Biology Students Really Hate Math? Empirical Insights Into Undergraduate Life Science Majors' Emotions About Mathematics, CBE Life Sciences Education 16(3) (2017) 1-10. DOI: 10.1187/Cbe.16-08-0248.

[16] K. E. Matthews, Y. Hodgson, And C. Varsavsky, Factors Influencing Students' Perceptions of Their Quantitative Skills, International Journal of Mathematical Education in Science and Technology 44(6) (2013) 782 795. DOI: 10.1080/0020739x.2013.814814.

[17] A. M. Hoskinson, How To Build A Course In Mathematical-Biological Modeling: Content And Processes for Knowledge and Skill, CBE Life Sciences Education 9(1) (2010) 333-341. DOI: $10.1187 /$ Cbe.10.

[18] M. L. Aikens And E. L. Dolan, Teaching Quantitative Biology: Goals, Assessments, And Resources, Molecular Biology of the Cell 25(22) (2014) 3478-3481. DOI: 10.1091/Mbc.E14-06-1045.

[19] C. D. Eaton And H. C. Highlander, The Case 
For Biocalculus: Design, Retention, And Student Performance, CBE Life Sciences Education 16(2) (2017) 1-22. DOI: 10.1187/Cbe.15-04-0096.

[20] C. D. Eaton And H. C. Highlander, The Case for Biocalculus: Design, Retention, and Student Performance, CBE Life Sciences Education 16(2) (2017). DOI: 10.1187/cbe.15-04-0096.

[21] L. Cohen, L. Manion, and K. Morrison, Research Methods in Education, Routledge, New York, 2018.

[22] A. Wigfield and J. S. Eccles, Expectancy-value Theory of Achievement Motivation, Contemporary Educational Psychology 25(1) (2000) 68-81. DOI: 10.1006/ceps.1999.1015.

[23] V. R. Luttrell, B. W. Callen, C. S. Allen, M. D. Wood, D. G. Deeds, and D. C. S. Richard, The Mathematics Value Inventory for General Education Students: Development and Initial Validation, Educational and Psychological Measurement 70(1) (2010) 142-160. DOI: $10.1177 / 0013164409344526$.

[24] H. Gaspard et al., More Value Through Greater Differentiation: Gender Differences in Value Beliefs About Math, Journal of Educational Psychology 107(3) (2015) 663-677. DOI: 10.1037/edu0000003. 